\title{
Assessment on Frequency of ABO Blood Group and RH (D) Negative Mothers among Pregnant Women Attending at Antenatal Care Clinic of Sodo Health Center, SNNPR, Ethiopia
}

\section{Kebreab Paulos*}

Department of Midwifery, College of Health and Medical Sciences, Wolaita Sodo University, Sodo, Ethiopia

*Corresponding Author: Kebreab Paulos, Department of Midwifery, College of Health and Medical Sciences, Wolaita Sodo University, Sodo, Ethiopia.

Received: February 26, 2020

Published: April 24, 2020

(C) All rights are reserved by Kebreab

Paulos.

\begin{abstract}
Background: It's important for women to find out their blood type at the start of their pregnancy. Blood will be taken to find out and there are four different types: $A, B, A B$ and $O$.

In addition to blood type, women can have Rh factor (specifically Rhesus $\mathrm{D}$ antigen), which is when proteins appear on the surface of the blood. Women who do have Rh factor are classified as Rh positive ( $\mathrm{A}+, \mathrm{B}+\mathrm{AB}+$ and $\mathrm{O}+$ ) and women who don't are $\mathrm{Rh}$ negative (A-, B-, AB- and O).

Objective: Assessment on frequency of $\mathrm{ABO}$ blood group and $\mathrm{Rh}$ (D) negative among pregnant women attending at antenatal care clinic of Sodo health center.

Method: A retrospective study was conducted at Sodo health center ANC clinic from Jan-April 2019. A total of 270 study participants was used. Systematic random sampling technique was used to select the study participants. Socio-demographic information was collected by using pretested questionnaires. The data was edited, cleaned, entered and analyzed by using SPSS 20 . Statistical test between dependent and independent variables has been done by using multivariable logistic registration. Moreover, table and different forms of graph was used to present data.

Result: Among a total of 270 study subjects, 0 comprised 41.1\% 'A' (28.5\%). 'B' and 'AB' accounts (24.5\%) and (5.9\%) respectively. $\mathrm{Rh}$ blood group results revealed that $7.0 \%$ of the participants were $\mathrm{Rh}$ negative.

Conclusion: This result showed that the most prevalent blood group is $\mathrm{O}$ while the least prevalent is $\mathrm{AB}$ blood group. The frequency of Rh (D) negative pregnant women was 7.0\%, among these blood group O Rh (D) negative was the most frequent. Generally, frequency of $\mathrm{Rh}(\mathrm{D})$ negative pregnant women in this study is higher than most studies which were conducted elsewhere at different sites of the world which needs a great concern for appropriate prevention and management of Rhesus incompatibility during antenatal visit of pregnant women.
\end{abstract}

Keywords: ABO Blood Group; Rh (D) Type; Sodo; Pregnant Women

\section{Introduction}

The membrane of the human red blood cell (RBC) contains a variety of blood group antigens. The most important and best known of these is A and B antigens, which are actually complex oligosaccharides that differ in their terminal sugar. The antibodies against red cell antigens are called agglutinins and individuals are divided into four major blood groups $\mathrm{A}, \mathrm{B}, \mathrm{AB}$ and $\mathrm{O}$ according to the presence of these antigens and agglutinins [1]. In addition, human red cells that contain antigen-D are known as Rhesus positive while those without antigen-D in their RBC's are Rhesus negative [2].

All human populations share the same blood group systems; although they differ in the frequencies of specific types. The incidence of $\mathrm{ABO}$ and $\mathrm{Rh}$ groups varies markedly in different races, ethnic groups in different part of the world. Identification of $\mathrm{Rh}$ system is important to prevent the erythroblastosis fetalis; which commonly arises when an Rh negative mother carries an Rh positive fetus [3].

The clinical relevance of these blood group systems relate to the capacity of alloantibodies (directed against antigens not possessed by the individual) to cause destruction of transfused red cells (ABO antibodies) or to cross the placenta and give rise to hemolytic disease of the fetus and newborn (HDFN) [4]. ABO incompatibility is a common condition in a newborn baby and causes minimal hemolysis. Rhesus incompatibility can pose a major problem in some pregnancies when the mother is Rh negative and the fetus is Rh-positive where it can lead to HDN, or erythroblastosis fetalis and it may be fatal to the fetus [5].

ABO incompatibility is a common condition in a newborn baby and causes minimal hemolysis. It may cause elevated levels of bili- 
rubin and anemia but less severe than Rh hemolytic disease. ABO incompatibility occurs when mother blood group 0 conceives fetus with blood group "A" or "B" is the most common cause for HDN among $\mathrm{ABO}$ blood group system and IgG antibody is responsible for this condition [6]

HDFN is a significant cause of perinatal mortality and morbidity [7] and in $50 \%$ of the cases, results from the transplacental passage of maternal $\mathrm{Rh}(\mathrm{D}) \mathrm{Ab}$, followed by their binding to fetal red blood cell Ag and subsequent destruction [8].

Hemolytic disease of new born due to blood group incompatibility is an important cause of morbidity and mortality of the fetus by causing hyperbilirubinemia. The degree to which the fetus is affected correlated with the amount of maternal antibody to that crosses the placenta. The incidence of Rhesus (D) hemolytic disease resulting from fetomaternal haemorrhage occurring in Rhesus negative women who carry a Rhesus positive fetus continue to be high [9].

The overall incidence HDFN have severally been reported to vary significantly from place to place ranging from as low as $7.2 / 10,000$ births to as high $14.3 / 10,000$ births and various populations and ethnic groups around the world [10].

ABO incompatibility occurs in $20 \%$ of pregnancies but only $20 \%$ of these develop hemolytic disease. In addition to severe jaundice, these infants may also develop significant anemia over the first several weeks of life [11].

Although the implementation of a program of routine antenatal anti-D prophylaxis has led to a significant decline in the numbers of women becoming sensitized in most developed countries, a significant number of women who are not fortunate enough to have access in sub-Saharan Africa continue to be affected. In these countries there are challenges associated with the management of sensitizing events (increasing incidence and trends of induced abortion, ectopic pregnancy and miscarriage) associated with Rh negative women [9].

Therefore, this study was undertaken to fill the information gaps through providing recent information about the incidence of $\mathrm{ABO}$ and $\mathrm{Rh}$ negativity. This will also help health workers and stack holders especially obstetricians for the effective management and prevention of complications associated with blood group incompatibilities.

\section{Materials and Methods}

Study area

Sodo or Wolaita Sodo is a town and separate woreda in southcentral Ethiopia. The administrative center of the Wolaita Zone of the Southern Nations, Nationalities, and Peoples Region, it has a latitude and longitude of $6^{\circ} 54^{\prime} \mathrm{N} 37^{\circ} 45^{\prime} \mathrm{E}$ with an elevation be- tween 1,600 and 2,100 meter (5,200 and 6,900 feet) above sea level. It was part of the former Sodo woreda which included Sodo Zuria which completely surrounds it. Currently, Sodo is known for being center of major health and education institutions in Ethiopia. Soddo Christian Hospital has one of the 10 surgical training centers in Africa. The hospital provide a full range of medical, and surgical service, including Orthopedic and General, Maternity, and Pediatrics. Wolaita Sodo University Teaching Referral Hospital is also located in this town and it serves around two million people. The total number of beds in the hospital was 200; out of which 60 beds were in Obstetrics and Gynecology department.

Study design and period

A cross sectional study was conducted among pregnant women who were attending antenatal clinic of Sodo health center from April-June 2019.

Population

\section{Source population}

All pregnant women who visited antenatal clinic of Sodo health center were taken as a source population.

\section{Study population}

All pregnant women who visited antenatal clinic of Sodo health center during the study period and those included in this study were the study population.

\section{Inclusion criteria}

All pregnant women who have been volunteer to be included in the study.

\section{Exclusion criteria}

All pregnant women who had no complete laboratory data (sex, year, ABO blood group, Rh blood group) on the ANC log book were excluded from this study.

\section{Sample size and sampling technique}

The sample size is determined by using a single population proportion formula by considering the following assumptions. $z \frac{\alpha}{2}=$ 1.96 , for the standard scale of $95 \%$ level of confidence, level of precision (d) $=5 \%$ and " $p$ " was considered as $80 \%$.

$$
\begin{aligned}
& \text { Sample size }(\mathrm{n})=\mathrm{z} \frac{\alpha^{2}}{2} \times \frac{\mathrm{p}(1-\mathrm{p})}{\mathrm{d}^{2}} \\
& \mathrm{n}=1.96^{2} \times \frac{0.8(1-0.8)}{0.05^{2}} \\
& \mathrm{n}=246
\end{aligned}
$$

By taking $10 \%$ non-response rate

$\mathrm{n}=246+(246 \times 10 \%)$

$246+24.6=270$

$=270$

The final sample size will be 270 . 
Systematic random sampling technique has been used to select the study participants. Complete list of ANC attending mothers was obtained from Sodo health center ANC clinic.

\section{Measurement}

Socio-demographic, ABO group and Rh type related information was collected using structured and pretested questionnaire using face to face interview. The questionnaire was customized to this study from previous study questionnaire. Data and our independent variables were collected from volunteer mothers by using questionnaires.

\section{Data collection process}

Four experienced female data collectors were collected the data after thorough training on the objective of the study and the questionnaire. Two degree holder health professionals supervised the data collectors. Data collectors and supervisors were trained for 5 days by using training manual prepared for this purpose.

\section{Data analysis}

The data has been edited, cleaned, entered and analyzed by using SPSS 20. Statistical test between dependent and independent variables was done by using multivariable logistic regression. A pvalue $\leq 0.05$ will be considered as indicative of statically significant. Moreover, table and different forms of graph ware used to present data. Data was checked for values that are inconsistent with other information gathered in the study. The data was also checked for missing item and decisions was made as to simply disregard missing data items during analysis.

\section{Data quality control}

The questionnaires were prepared by English language and later were translated to the local language (Amharic) and again it has been re translated to English to check the consistency. The questionnaire was pre-tested prior to actual work. Training was given to data collectors and supervisors. Observation and supervision was done throughout the fieldwork, training and data collection process. In addition, meeting with each member of the team on a daily basis to discuss performance and give out future work assignments was performed.

\section{Ethical considerations}

The study was conducted after ethical approval obtained from Laboratory Science Research and Ethics Committee. Data was collected after the permission of head of Sodo health center before starting the actual work. Informed consent was obtained from each study participant before collecting socio-demographic data and each study participant has the right to withdraw from the study any time. To ensure confidentiality of data, study subjects was identified using codes and unauthorized persons would not have access to the collected data

\section{Results}

A total of two hundred seventy laboratory results of pregnant women were included in this study. The distribution of ABO blood group shows that ' $O$ ' group blood comprised $41.1 \%(111 / 270)$ among the participants and 'A' being the second leading blood group with $28.5 \%$ (77/270). Blood group 'B' and 'AB' consisted of $24.5 \%(66 / 270)$ and $5.9 \%(16 / 270)$ of the participants respectively (Table 1). Frequency of Rh (D) result revealed that $7.0 \%$ $(19 / 270)$ of the participants were Rh (D) negative (Table 1). All $\mathrm{ABO}$ blood group results were not statistically associated with $\mathrm{Rh}$ (D) blood group results.

\begin{tabular}{|c|c|c|c|}
\hline \multirow{2}{*}{$\begin{array}{c}\text { ABO blood } \\
\text { group }\end{array}$} & $\begin{array}{c}|c| \\
\text { Rh(D) grouping }\end{array}$ & \multirow{2}{*}{ Total } \\
\cline { 2 - 3 } & Rh(D) positive & $\begin{array}{c}\text { Rh(D) negative } \\
\text { (N = 19) }\end{array}$ & \\
\hline $\mathrm{A}$ & $71(26.3 \%)$ & $6(2.2 \%)$ & 77 \\
\hline $\mathrm{B}$ & $62(23 \%)$ & $4(1.4 \%)$ & 66 \\
\hline $\mathrm{AB}$ & $15(5.5 \%)$ & $1(0.3 \%)$ & 16 \\
\hline 0 & $103(38.3 \%)$ & $8(2.9 \%)$ & 111 \\
\hline
\end{tabular}

Table 1: Relationship between $\mathrm{ABO}$ and $\mathrm{R}(\mathrm{D})$ blood grouping ( $n=270$ ) in Sodo health center, April-June 2019.

\section{Discussion}

The present study has been carried out to determine the distribution pattern of ABO blood group and Rh negativity among pregnant women who attended Sodo health center. From this study, the distribution of blood group 0 was the highest with percentage frequency of $41.1 \%$, followed by blood group A and B with percentage frequency of $28.5 \%$ and $24.5 \%$ respectively and the least percentage frequency is that of blood group $\mathrm{AB}$ which is $5.9 \%$ and $\mathrm{Rh}-\mathrm{re}-$ sult revealed that $7.0 \%$ of the participants were $\mathrm{Rh}(\mathrm{D})$ negative. All of the ABO blood groups had not statistical significant association with $\mathrm{Rh}(\mathrm{D})$ negative blood group. Although the distribution of ABO blood groups varies from one population to the other, in most studies blood group 0 has been reported as the predominant group. This study was in line with a study conducted in Saudi Arabia king Abdul Aziz university hospital with $7.5 \%$ of the pregnant women being $\mathrm{Rh}(\mathrm{D})$ negative [13].

On the other hand the result of this study (70\%) was a little bit higher than a study conducted in Nigeria where an overall Rh(D) negative prevalence among pregnant women was 4.5\% [14]. This study is higher than a similar study conducted in Thailand and Nigeria with $0.31 \%$ and $2.9 \%$ of pregnant women being $\mathrm{Rh}(\mathrm{D})$ negative $[12,15]$.

The $\mathrm{Rh}(\mathrm{D})$ negativity among each blood groups analyzed in this study showed that, $\mathrm{Rh}(\mathrm{D})$ negative blood group $\mathrm{O}$ was the most predominant (42.2\%) and $\mathrm{Rh}(\mathrm{D})$ negative blood group $\mathrm{A}, \mathrm{B}$ and $\mathrm{AB}$ accounted $32.3 \%, 20.5 \%$, and $5 \%$ respectively and this finding is in line with a study conducted in Saudi Arabia king Abdul Aziz uni- 
versity hospital with $\mathrm{Rh}(\mathrm{D})$ negative blood group 0 , A, Band $\mathrm{AB}$ accounted $46.7 \%, 30 \%, 18 \%, 5 \%$ respectively [13]. The possible explanation for these similar findings may be the population of these two countries might have similar genetic derivation.

The frequency of $\mathrm{Rh}(\mathrm{D})$ negative 0 blood group among $\mathrm{Rh}(\mathrm{D})$ negatives in this study is lower than similar study conducted in $\mathrm{Ni}-$ geria which is $42 \%$ whereas the rest blood groups are compared to be higher [14] on the other hand incidence rate of blood group o pregnant women $41.1 \%$ identified in this study was found to be lower than a study conducted in Nigeria where blood group 0 accounted 59.1\%, but prevalence of blood groups A, B and AB in the current study is higher than a study conducted Nigeria [15]. Since blood group is not affected by socioeconomic demographic variables, this difference could be generally attributed by genetic differences. Generally, in this study the frequency of Rh(D) negative pregnant women is higher than most of those studies which were conducted at different sites of the world which needs a great concern for appropriate prevention and management of alloimmunization during antenatal care.

\section{Limitation of the Study}

- Because of luck of appropriate handling some pages of ANC loge book were lost.

- Certain figures of ANC loge book were difficult to read.

- Inconsistent supply of blood grouping reagents resulted pregnant women to visit other health care institutions.

- Some women were not volunteer to be included in the study.

- Lack of financial capacity of group members concerned with the fees expected for different purpose.

\section{Conclusion}

This result showed that the most prevalent blood group is 0 while the list prevalent is $\mathrm{AB}$ blood group. The frequency of $\mathrm{Rh}(\mathrm{D})$ negative pregnant women was $7.0 \%$, among these blood group $\mathrm{O} \mathrm{Rh}(\mathrm{D})$ negative was the most frequent. Generally, frequency of $\mathrm{Rh}(\mathrm{D})$ negative pregnant women in this study is higher than most studies which were conducted elsewhere at different sites of the world which needs a great concern for appropriate prevention and management of Rhesus incompatibility during antenatal visit of pregnant women.

\section{Recommendation}

Health education has to be given for the population to have birth in health centers since it can aid in the prevention and management of hemolytic disease of new born.

Therefore, all pregnant women earn health facility delivery habit to have safe delivery service, rather it may cause fatality concerned with Rh incompatibility.
Additionally, it is better to know his/her own blood group before marriage since it reduces hemolytic disease of fetus and newborn of couples who have no easily transportation access to attend antenatal care and delivery service in health facility.

\section{Bibliography}

1. Pramanik $\mathrm{T}$ and Pramanik S. "Distribution of $\mathrm{ABO}$ and $\mathrm{Rh}$ blood groups in Nepalese Medical Students". Eastern Mediterranean Health Journal 6.1 (2000): 156-158.

2. Osaro E and Charles AT. "Rh isoimmunization in Sub-Saharan Africa indicates need for universal access to anti-RhD immunoglobulin and effective management of D-negative pregnancies". International Journal of Women's Health 2 (2010): 428437.

3. Patel PA., et al. "Frequency and distribution of blood groups in blood donors in western Ahmedabad". National Journal of Medical Research 2.2 (2012): 200-203.

4. Knowles S and Poole G. "Human blood group systems". In: Practical transfusion medicine $1^{\text {st }}$ edition. Blackwell Science, London, UK (2002): 24-31.

5. YMLo Dennis YM., et al. "Prenatal diagnosis of fetal RhD status by molecular analysis of maternal plasma". New England Journal of Medical Science 339.24 (1998): 1734-1738.

6. Mohammad I., et al. "Prevalence of rhesus type and ABO Incompatibility in jaundiced neonates". Journal of Postgraduate Medical Institute 3.25 (2011): 233-239.

7. Maddocks DG., et al. "The SAFE project: towards non-invasive prenatal diagnosis". Biochemical Society Transactions 37.2 (2009): 460-465.

8. Erhabor O., et al. "Abortion, ectopic pregnancy and miscarriages in Sub Saharan Africa: Challenges of Rhesus isoimmunisation in Rhesus negative women". Open Journal of Obstetrics and Gynecology 3.9 (2013): 15-26.

9. Koelewijn JM., et al. "Effect of screening for red cell antibodies other than anti-D to detect hemolytic disease of the foetus and newborn". Transfusion 48.5 (2009): 941-952.

10. Hay WW., et al. "Current pediatric diagnosis and treatment". $18^{\text {th }}$ edition. New York: Lange Medical Books/McGraw- Hill (2007): 11-17.

11. Puangsricharern A and Suksawat S. "Prevalence of Rh negative pregnant women who attended Ante Natal Clinic and delivered in Rajavithi Hospital". Journal of the Medical Association of Thailand 90.8 (2007): 1491-1494. 
12. Nabeel S and Bondagji. "Rhesus alloimmunization in pregnancy a tertiary care center experience in the western region of Saudi Arabia". Saudi Medical Journal 32.10 (2011): 1039-1045.

13. Okeke TC., et al. "The prevalence of Rhesus negativity among pregnant women in Enugu, South east Nigeria". Nigerian Journal of Clinical Practice 15.4 (2012): 400-402.

14. Temitayo OI and Timothy SO. "Frequency distribution of hemoglobin variants and $\mathrm{Rh}$ blood groups among pregnant women". American Medical Journal 4.1 (2013): 78-81.

15. Erhabor 0., et al. "Distribution of ABO and Rhesus blood groups among residents of Gusau, Zamfara state, North Western Nigeria". Journal of Medical and Health Sciences 2.4 (2013): $58-61$.

\section{Assets from publication with us}

- Prompt Acknowledgement after receiving the article

- Thorough Double blinded peer review

- Rapid Publication

- Issue of Publication Certificate

- High visibility of your Published work

Website: https://www.actascientific.com/

Submit Article: https://www.actascientific.com/submission.php Email us: editor@actascientific.com

Contact us: +919182824667 